OPEN ACCESS

Edited by:

Vladimir Lesnyak,

Dresden University of

Technology, Germany

Reviewed by:

Hongbo Li,

Beijing Institute of Technology, China Aliaksei Dubavik,

ITMO University, Russia

*Correspondence:

Karl David Wegner wegner.karldavid@gmail.com

Marie Carrière

marie.carriere@cea.fr

Peter Reiss

peter.reiss@cea.fr

tPresent Address:

Karl David Wegner

Biophotonics (BAM-1.2), BAM Federal Institute for Materials Research and

Testing, Berlin, Germany

Specialty section:

This article was submitted to

Nanoscience,

a section of the journal

Frontiers in Chemistry

Received: 22 February 2019

Accepted: 12 June 2019

Published: 27 June 2019

Citation:

Wegner KD, Dussert $F$

Truffier-Boutry $D$, Benayad A, Beal $D$,

Mattera $L$, Ling $W L$, Carrière $M$ and

Reiss $P$ (2019) Influence of the

Core/Shell Structure of Indium

Phosphide Based Quantum Dots on

Their Photostability and Cytotoxicity.

Front. Chem. 7:466.

doi: 10.3389/fchem.2019.00466

\section{Influence of the Core/Shell Structure of Indium Phosphide Based Quantum Dots on Their Photostability and Cytotoxicity}

\author{
Karl David Wegner ${ }^{1 *}$, Fanny Dussert ${ }^{2}$, Delphine Truffier-Boutry ${ }^{3}$, Anass Benayad ${ }^{3}$, \\ David Beal $^{2}$, Lucia Mattera ${ }^{1}$, Wai Li Ling ${ }^{4}$, Marie Carrière ${ }^{2 *}$ and Peter Reiss ${ }^{1 *}$ \\ ${ }^{1}$ Univ. Grenoble Alpes, CEA, CNRS, IRIG, SYMMES, STEP, Grenoble, France, ${ }^{2}$ Univ. Grenoble Alpes, CEA, CNRS, IRIG, \\ SyMMES, CIBEST, Grenoble, France, ${ }^{3}$ Univ. Grenoble Alpes, CEA-LITEN L2N, Grenoble, France, ${ }^{4}$ Univ. Grenoble Alpes, \\ CEA, CNRS, IRIG, IBS, Grenoble, France
}

With the goal to improve their photostability, InP-based QDs are passivated with three types of inorganic shells, namely (i) a gradient $\mathrm{ZnSe}_{x} \mathrm{~S}_{1-x}$ shell, (ii) an additional ZnS shell on top of the gradient shell with two different thicknesses (core/shell/shell, CSS), (iii) an alumina coating on top of ZnS. All three systems have photoluminescence quantum yields (PLQY) > 50\% and similar PL decay times (64-67 ns). To assess their photostability they are incorporated into a transparent poly (methyl methacrylate) (PMMA) matrix and exposed to continuous irradiation with simulated sunlight in a climate chamber. The alumina coated core/shell system exhibits the highest stability in terms of PLQY retention as well as the lowest shift of the PL maximum and lowest increase of the PL linewidth, followed by the CSS QDs and finally the gradient shell system. By means of XPS studies we identify the degradation of the ZnS outer layer and concomitant oxidation of the emissive InZnP core as the main origins of degradation in the gradient structure. These modifications do not occur in the case of the alumina-capped sample, which exhibits excellent chemical stability. The gradient shell and CSS systems could be transferred to the aqueous phase using surface ligand exchange with penicillamine. Cytotoxicity studies on human primary keratinocytes revealed that exposure for $24 \mathrm{~h}$ to $6.25-100 \mathrm{nM}$ of QDs did not affect cell viability. However, a trend toward reduced cell proliferation is observed for higher concentrations of gradient shell and CSS QDs with a thin ZnS shell, while CSS QDs with a thicker ZnS shell do not exhibit any impact.

Keywords: quantum dots, photostability, cytotoxcity, indium phosphide, core/shell structure, alumina coating

\section{INTRODUCTION}

In the quest for toxic-heavy-metal-free quantum dots (QDs), indium phosphide has been shown to be a valid alternative to cadmium-based materials (Reiss et al., 2016; Allocca et al., 2019). The chemical synthesis of InP QDs and their core/shell structures has been strongly developed in the past decade with the goal to bring the optical properties to a level comparable with CdSe based QDs (Cossairt, 2016; Tamang et al., 2016). Concerning the core synthesis, it has been established that the addition of zinc, in form of carboxylate (e.g., stearate, undecylenate, oleate) improves 
both the size distribution and hence the emission linewidth and the emission efficiency ( $\mathrm{Li}$ and Reiss, 2008; Xu et al., 2008; Ung et al., 2010b; Stein et al., 2016). Nonetheless, for achieving high photoluminescence quantum yields (PLQY) and enhanced photostability the precise engineering of core/shell heterostructures is a prerequisite, and ideally, the InP or InZnP core should be covered by a thick shell of a large band gap, chemically stable semiconductor such as ZnS (Reiss et al., 2009). The synthesis of InP/ZnS nanocrystals in a single-step one-pot method by adding a sulfur source (dodecanethiol, DDT) during the core synthesis leads to an alloy structure capped with a thin $\mathrm{ZnS}$ shell (Huang et al., 2010). Due to the large lattice mismatch of $7.7 \%$ between zinc blende InP and $\mathrm{ZnS}$ it is challenging to obtain a thick shell. ZnSe has a lower mismatch (3.3\%) and several works reported the growth of either pure $\mathrm{ZnSe}$ or graded $\mathrm{ZnSe}_{\mathrm{x}} \mathrm{S}_{1-\mathrm{x}}$ shells on InP or InZnP (Lim et al., 2011; Tessier et al., 2015; Pietra et al., 2016; Chandrasekaran et al., 2017). However, $\mathrm{ZnSe}$ provides a weaker carrier confinement than $\mathrm{ZnS}$ due to the smaller band gap and is more sensitive to oxidation than $\mathrm{ZnS}$ (Toufanian et al., 2018). Therefore, it has been suggested to add a thicker outer $\mathrm{ZnS}$ shell on a graded intermediate $\mathrm{ZnSe}_{\mathrm{x}} \mathrm{S}_{1-\mathrm{x}}$ shell (Lim et al., 2013; Ramasamy et al., 2017; Wang et al., 2017). The latter acts as a lattice adapter between the core and the outer shell leading to a core/shell/shell (CSS) system, as already demonstrated in the case of II-VI semiconductors (Reiss et al., 2003; Talapin et al., 2004). Li et al. proposed another way to enhance the photostability of CdSe- or $\mathrm{CuInS}_{2}$ - based QDs by generating an alumina coating on their surface (Li et al., 2015; Yan et al., 2016). In this case, the nanocrystal surface is treated with an appropriate aluminum precursor (e.g., aluminum isopropoxide), which transforms to alumina via oxidation. The different abovementioned strategies for the surface passivation of InP and InZnP QDs are summarized in Figure 1.

The goal of the present work is to investigate the impact of the different core/shell systems discussed-core/gradient shell and CSS structures with different thickness of the outer $\mathrm{ZnS}$ shell and a newly developed alumina coating-on the photostability and cytotoxicity behavior of InZnP QDs. Aging experiments were carried out in a controlled and reproducible manner by integrating the QDs into a solid polymer matrix (PMMA) and irradiating them with simulated solar light in a climatic chamber. Finally, the cytotoxicity of the obtained QDs was assessed using human primary keratinocytes.

\section{MATERIALS AND METHODS}

\section{Chemicals}

Indium acetate (99.99\%), zinc acetate (99,9\%), myristic acid (>99\%), tris (trimethylsilyl)phosphine $\left(95 \%,(\mathrm{TMS})_{3} \mathrm{P}\right), \quad 1-$ octadecene (90\%, ODE), trioctylphosphine (97\%, TOP), sulfur (99.99\%), selenium (99.99\%), dimethylformamide (DMF), poly (methyl methacrylate) (PMMA, $\mathrm{M}_{\mathrm{W}} \sim 350,000 \mathrm{GPC}$ ), aluminum isopropoxide ( $\mathrm{Al}$ (IPA) 3 98\%), toluene, methanol, chloroform, acetone, hexane, D-penicillamine, tetramethylammonium hydroxide (TMAOH), phosphate-buffered saline solution (1xPBS), and tris (2-carboxyethyl) phosphine hydrochloride solution $0.5 \mathrm{M}$ (TCEP) were purchased from Sigma-Aldrich.
Zinc stearate $\left(90 \%, \mathrm{ZnSt}_{2}\right)$ was acquired from Riedel de Haën. Oleic acid (70\%) came from Fisher Chemicals. All chemicals were used as received without any further purification, unless stated otherwise.

\section{Zinc Ethylxanthate}

Zinc ethylxanthate was prepared according to the procedure reported in Protiere and Reiss (2006).

\section{Preparation of Indium-Myristate}

Indium acetate $(6.9 \mathrm{mmol})$, myristic acid $(21.4 \mathrm{mmol})$, and ODE $(15 \mathrm{~mL})$ were mixed in a $50 \mathrm{~mL}$ three neck flask. The solution was stirred and degassed under vacuum for $3 \mathrm{~h}$ at $120^{\circ} \mathrm{C}$. After cooling down to room temperature the precipitated indiummyristate was washed with ca. $150 \mathrm{~mL}$ of dry hexane before drying under vacuum.

\section{Preparation of Zinc-Oleate}

Zinc acetate $(5 \mathrm{mmol})$, oleic acid $(10 \mathrm{mmol})$, and $9.35 \mathrm{~mL} \mathrm{ODE}$ were mixed in a $50 \mathrm{~mL}$ three neck flask. The solution was stirred and degassed under vacuum at $120^{\circ} \mathrm{C}$ for $1 \mathrm{~h}$. After cooling down to room temperature the flask was backfilled with Ar and the mixture was stored in the glove box.

\section{Preparation of TOP-Se and TOP-S}

For a $0.4 \mathrm{M}$ TOP-Se stock solution, $2 \mathrm{mmol}$ of selenium powder were dissolved in $5 \mathrm{~mL}$ of trioctylphosphine (TOP) for $24 \mathrm{~h}$. The preparation of a $0.4 \mathrm{M}$ TOP-S stock solution was prepared similarly using elemental sulfur.

\section{Synthesis of InZnP Core Nanocrystals}

Indium-myristate $(0.1 \mathrm{mmol}), \mathrm{ZnSt}_{2}(0.2 \mathrm{mmol})$, and $8.5 \mathrm{~mL}$ ODE were mixed in a $50 \mathrm{~mL}$ three-neck flask and degassed for $1 \mathrm{~h}$. The flask was backfilled with Ar and the reaction mixture was rapidly heated to $300^{\circ} \mathrm{C}$ in a molten salt bath. At $100^{\circ} \mathrm{C}$ $0.1 \mathrm{mmol}$ (TMS) ${ }_{3} \mathrm{P}$, dissolved in $1 \mathrm{~mL}$ ODE, was swiftly injected. After 20 min the reaction was quenched by removing the salt bath and letting cool down to room temperature.

\section{Synthesis of $\operatorname{lnZnP} / Z_{n S e} S_{1-x}$ Core/Gradient Shell Nanocrystals}

The InZnP core was prepared as mentioned before but instead of cooling down to room temperature the mixture was kept at $220^{\circ} \mathrm{C}$. $2.5 \mathrm{~mL}$ of the $0.4 \mathrm{M}$ zinc-oleate $(1 \mathrm{mmol})$ stock solution was added dropwise followed by the swift injection of $0.444 \mathrm{~mL}$ of TOP-Se $(0.2 \mathrm{mmol})$ stock solution mixed with $0.5 \mathrm{~mL}$ ODE and $1.57 \mathrm{~mL}$ of TOP-S $(0.7 \mathrm{mmol})$ stock solution. The reaction mixture was heated to $300^{\circ} \mathrm{C}$ using a heating mantle with a heating ramp of $10^{\circ} \mathrm{C}$ per minute. The overall shell growth time was ca. $30 \mathrm{~min}$ and the reaction was quenched by cooling down to room temperature. The NCs were purified three times by a precipitation $(1: 1 \mathrm{v} / \mathrm{v}$ mixture of methanol/chloroform and acetone) and redispersion (chloroform) cycle and finally stored in hexane. 


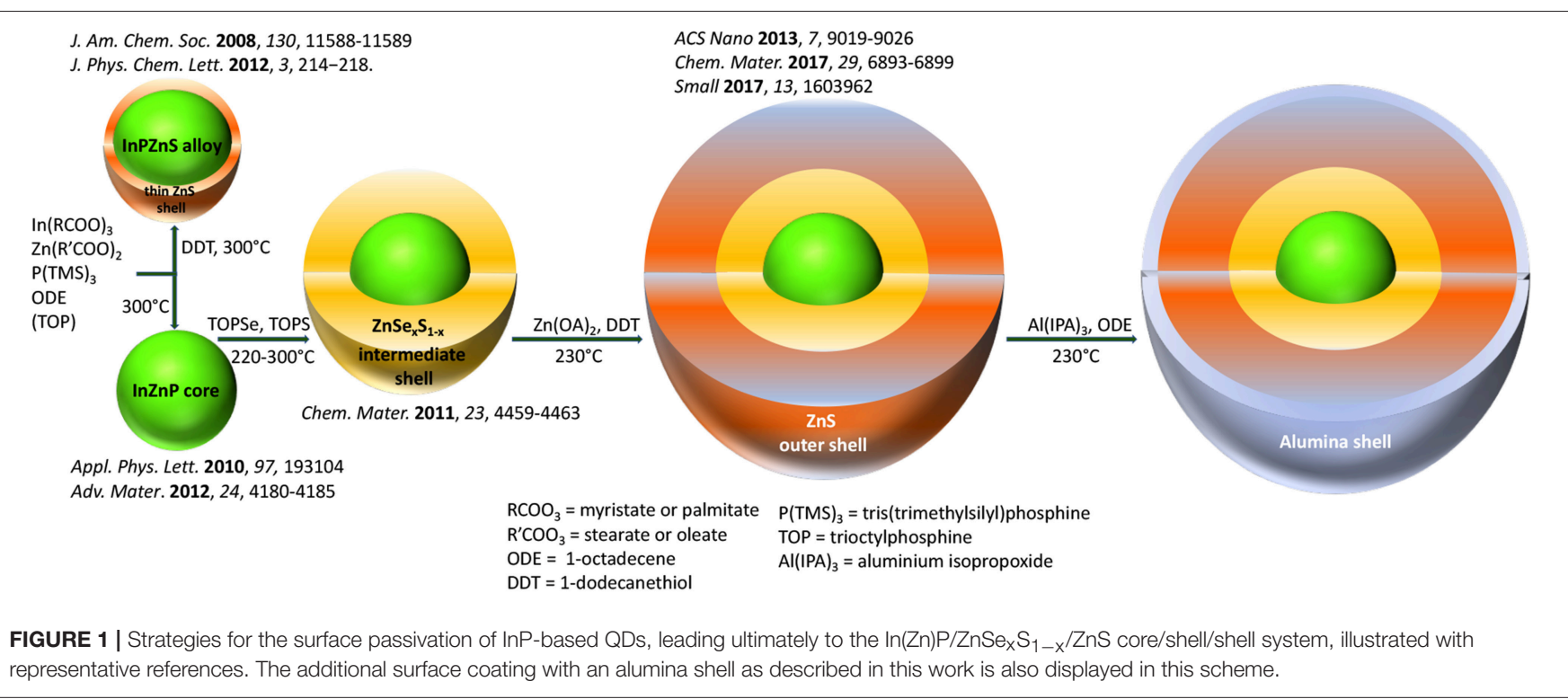

\section{Synthesis of InZnP/ ZnSe $S_{1-x} / Z n S$ Core/Shell/Shell Nanocrystals of Variable ZnS Shell Thickness}

The synthesis of the InZnP/ZnSe $\mathrm{S}_{1-x} \mathrm{NCs}$ was performed as described above but instead of cooling down to room temperature the mixture was kept at a temperature of $230^{\circ} \mathrm{C}$ using a heating mantle. In order to prepare the second (thin) $\mathrm{ZnS}$ shell, a mixture of $0.1 \mathrm{mmol}$ zinc ethylxanthate dissolved in $100 \mu \mathrm{L}$ DMF and $1 \mathrm{~mL}$ toluene was added to $0.8 \mathrm{mmol} \mathrm{ZnSt}_{2}$ dissolved in $3 \mathrm{~mL}$ ODE and injected into the reaction mixture using a syringe pump with a pump rate of $8 \mathrm{~mL} / \mathrm{h}$. After $30 \mathrm{~min}$ of shell growth the reaction was quenched by cooling down to room temperature and the NCs purified as described above for the gradient shell. To grow a thick $\mathrm{ZnS}$ shell the amount of zinc ethylxanthate and zinc stearate solution was doubled and the shell growth time was extended to $60 \mathrm{~min}$ before quenching the reaction by cooling down to room temperature.

\section{Synthesis of $\operatorname{InZnP/ZnSe} \mathrm{S}_{1-x} / \mathrm{ZnS}$-Alumina}

InZnP/ZnSe $\mathrm{S}_{1-\mathrm{x}} \mathrm{NCs}$ synthesis was performed as described above and the mixture was kept at $230^{\circ} \mathrm{C}$ after gradient shell growth for $30 \mathrm{~min}$. With a syringe pump, a shell mixture used for the preparation of a thin second $\mathrm{ZnS}$ shell was injected over the course of $30 \mathrm{~min}(0.1 \mathrm{mmol}$ zinc ethylxanthate dissolved in $100 \mu \mathrm{L}$ DMF and $1 \mathrm{~mL}$ toluene was mixed with $0.8 \mathrm{mmol} \mathrm{ZnSt}_{2}$ dissolved in $3 \mathrm{~mL} \mathrm{ODE}$ ). When the injection of shell mixture started, $1 \mathrm{~mL}$ of a solution prepared by dissolving $1.12 \mathrm{mmol}$ $\mathrm{Al}$ (IPA) $)_{3}$ in $3 \mathrm{~mL} \mathrm{ODE}$ at $40^{\circ} \mathrm{C}$ was slowly injected. At 10 and 20 min of the shell growth another $1-\mathrm{mL}$ volume of the Almixture was injected. The mixture was kept for a total of $60 \mathrm{~min}$ at $230^{\circ} \mathrm{C}$ before cooling down to room temperature and purifying as mentioned before.

\section{Embedding InP-Based QDs in PMMA}

To prepare a 30wt \% PMMA solution, $3 \mathrm{~g}$ of PMMA were dissolved in $7 \mathrm{~mL}$ chloroform, stirred for $1 \mathrm{~h}$ and ultrasonicated several times in between for $2 \mathrm{~min}$. The QD solutions had a concentration of approximately of $20 \mathrm{mg} / \mathrm{mL}$ and in order to prepare a PMMA disc with 0.4 wt $\%\left(\sim 10^{-6} \mathrm{~mol} \cdot \mathrm{L}^{-1}\right)$, ca. $12 \mathrm{mg}(620 \mu \mathrm{L})$ InP-based NCs were added to the PMMA solution. The mixture was stirred for another hour and ultrasonicated in between until the QDs were homogenously distributed. $1.5 \mathrm{~mL}$ of the QD-PMMA solution was filled in a Teflon mold (diameter $20 \mathrm{~mm}$ ) and kept for 3 days in the dark to enable the slow evaporation of chloroform. The dried PMMA discs were checked to ensure the absence of any bubbles, which can appear in case the chloroform evaporates too fast. They were then unmolded and cut using a gauge in order to have the same geometry and volume for all samples (disc diameter: $15 \mathrm{~mm}$, thickness: $1 \mathrm{~mm}$ ).

\section{Phase Transfer Using Penicillamine}

The InZnP QDs with different shells (except for alumina coating) were rendered water-soluble via ligand exchange using $\mathrm{D}$ penicillamine. Therefore, a $0.2 \mathrm{M}$ solution of $\mathrm{D}$-penicillamine was prepared in $1 \mathrm{~mL}$ of degassed MilliQ water. After addition of $200 \mu \mathrm{L}$ TCEP the $\mathrm{pH}$ was adjusted to 9 with TMAOH (25 wt $\%$ in methanol) solution. After thorough degassing, $0.5 \mathrm{~mL}$ of the ligand solution was added to $1 \mathrm{~mL}$ degassed colloidal solution of QDs dissolved in chloroform with a concentration of ca. $3-5 \mu \mathrm{M}$. The biphasic mixture was stirred vigorously for $45 \mathrm{~min}$ at room temperature. The mixture was quickly centrifuged to obtain a clear phase separation. The upper layer containing the QDs in the aqueous phase was separated from the organic phase and purified from excess ligands using a $\mathrm{NAP}^{\mathrm{TM}} 10$ size exclusion column (Sephadex ${ }^{\mathrm{TM}}$ G-25 DNA Grade from GE Healthcare). The column was equilibrated with a 1X PBS buffer, which was further used as eluent and storage buffer. The transferred QD samples were stored at $4^{\circ} \mathrm{C}$.

\section{Characterization}

\section{Photophysical Characterization}

Absorbance measurements were performed using a Hewlett Packard 8452A spectrometer and the emission spectra were 
recorded using a Fluorolog FL3-22 spectrometer from HoribaJobin Yvon equipped with a $150 \mathrm{~W}$ xenon lamp for steady-state measurements and a NanoLED laser diode from Horiba with a wavelength of $350 \mathrm{~nm}$ and $1 \mathrm{MHz}$ repetition for time-resolved measurements. Decay curves were fitted using Decay Analysis software from Horiba Scientist and intensity averaged decay times calculated according to Equation 1.

$$
\tau<\text { int }>=\frac{\sum_{i} A_{i}^{*} \tau_{i}^{2}}{\sum_{i} A_{i}^{*} \tau_{i}}
$$

In Equation $1 \mathrm{~A}_{\mathrm{i}}$ is the amplitude of the respective decay time $t_{i}$. Photoluminescence quantum yield measurements were performed at room temperature using an integration sphere, Hamamatsu Quantaurus Absolute PL quantum yield spectrometer.

\section{Structural Characterization}

Powder X-ray diffraction was performed using a Panalytical X'Pert diffractometer equipped with copper anode $\left(\lambda \mathrm{K}_{\alpha 1}=\right.$ $1.5406 \mathrm{~A}, \lambda \mathrm{K}_{\alpha 2}=1.5444 \mathrm{~A}$ ) and an X'Celerator 1D detector. The elemental composition was analyzed using a Zeiss Ultra $55+$ scanning electron microscope equipped with an EDX probe. The XRD and EDX samples were prepared by drop-casting a concentrated NCs dispersion either on a disoriented silicon substrate or on a cleaned silicon substrate. Transmission electron microscopy (TEM) was performed at cryogenic temperature on a FEI Polara microscope operating at $300 \mathrm{kV}$ and images were recorded on a Gatan K2 camera. For sample preparation, around $4 \mu \mathrm{L}$ of a diluted QD dispersion was applied onto a 400-mesh copper TEM grid covered with a homemade carbon film and the solvent was allowed to evaporate.

\section{XPS Studies}

Chemical characterization by XPS was carried out using a Versaprobe II ULVAC-PHI spectrometer. A monochromatic beam (X-ray source $\mathrm{Al}-\mathrm{K}_{\alpha} 1486.6 \mathrm{eV}$ ) of $100 \mu \mathrm{m}$ diameter and $97 \mathrm{~W}$ power was focused on the surface of the samples. Survey spectra were measured over a spectral range of $0-1200 \mathrm{eV}$ to identify the elements present in the material using a pass energy of $117 \mathrm{eV}$ which corresponds to a resolution of $1.6 \mathrm{eV}$. Highresolution spectral analyses were performed using a pass energy of $23 \mathrm{eV}$ which corresponds to a resolution of $0.5 \mathrm{eV}$. All XPS measurements were carried out in an ultra-high vacuum chamber $\left(7.10^{-8}\right.$ mbar).

All XPS spectra binding energies were corrected using the C 1s line of alkyl groups of PMMA at $285.0 \mathrm{eV}$. Curve fitting and background subtraction were accomplished using Casa XPS software. The spectra curve fitting was performed using Voigt function, convolution product of Gaussian (80\%) and Lorentzian (20\%) distributions.

\section{Aging Tests in a Climatic Chamber}

The QD-PMMA disks were placed in a Q-SUN Xe-1 Xenon arc test chamber (Q-LAB) providing full sunlight spectrum and continuously irradiated up to $32 \mathrm{~h}$. Weathering conditions were adapted from the ISO norm 4892-2:2006, developed for studying the aging of plastics. The irradiance and temperature were fixed at $1.44 \mathrm{~W} / \mathrm{m}^{2}$ (measured at $420 \mathrm{~nm}$ ) and $40^{\circ} \mathrm{C}$, respectively, with no humidity control. PL measurements were performed after an irradiance time of $6,12,24$, and $32 \mathrm{~h}$.

\section{Toxicity Testing}

Human skin samples were obtained following breast surgery from healthy female donors with their informed consent (Centre Hospitalier Universitaire de Grenoble, Grenoble, France). Keratinocytes were isolated as previously described (Mouret et al., 2006). They were grown at $37^{\circ} \mathrm{C}, 5 \% \mathrm{CO}_{2}$, in keratinocyte serum-free medium (KSF-M) supplemented with $1.5 \mathrm{ng} / \mathrm{ml} \mathrm{EGF,}$ $25 \mu \mathrm{g} / \mathrm{ml}$ bovine pituitary extract, $75 \mu \mathrm{g} / \mathrm{ml}$ primocin. For all experiments, cells were used at passages 1 or 2 . They were seeded in 96-well plates at 5,000 cells per well. When they reached $60 \%$ of confluence, they were exposed for $24 \mathrm{~h}$ to $6.25-$ $100 \mathrm{nM}$ of QDs. Exposure medium was then sampled and used to assess the release of lactate dehydrogenase (LDH) from cells (LDH assay kit, Sigma-Aldrich), which is a marker of cell membrane integrity, i.e., cell viability. The ability of these cells to proliferate was evaluated by quantifying the incorporation of 5Bromo-2'-deoxy-uridine (BrdU) in their DNA (BrdU assay kit, Roche). Both assays were performed following manufacturer's instructions. Triton X100 (0.1\%) was used as positive control.

\section{RESULTS AND DISCUSSION \\ Characterization of the Different Core/Shell Systems}

Figure 2 shows the UV-vis absorption and photoluminescence (PL) spectra as well as EDX data of InZnP/ZnSe $\mathrm{S}_{\mathrm{x}} \mathrm{S}_{1-\mathrm{x}}$ core/gradient shell QDs before and after growth of an additional $\mathrm{ZnS}$ shell. In contrast to literature methods, the monomolecular precursor zinc ethylxanthate has been applied for $\mathrm{ZnS}$ growth. As expected, the absorption spectra show an enhanced absorbance below $350 \mathrm{~nm}$ with increasing $\mathrm{ZnS}$ shell thickness. The EDX data (Figure 2C) also confirms unambiguously the successful growth of the thin and thick $\mathrm{ZnS}$ shells on the core/gradient shell system (Figures 4C,D). The same core diameter $(2.67 \pm 0.32 \mathrm{~nm}$ from TEM measurements) was used for all samples. In accordance with the elemental increase determined from EDX and TEM data, the thicknesses of the shells are around 2 monolayers (gradient shell), 3 monolayers (thin ZnS shell) and 4-5 monolayers (thick $\mathrm{ZnS}$ shell). Due to the fact that the gradient shell already provides a very good surface passivation, the additional $\mathrm{ZnS}$ growth only slightly improves the PL intensity (PLQY: 50.9\% gradient shell, $56.5 \%$ CSS thin, $63.6 \%$ CSS thick). A small blue shift of the PL maximum with increasing shell thickness (cf. Table S1, up to $9 \mathrm{~nm}$ for the thick $\mathrm{ZnS}$ shell) likely originates from the strain exerted on the core due to the smaller lattice parameter of $\mathrm{ZnS}$. This hypothesis is confirmed by powder X-ray analyses, showing a shift of the diffraction peaks characteristic of InZnP to wider angles upon ZnS shell growth (cf. Figure 2D). Time-resolved PL studies (Figure S1, Table S2) reveal similar averaged decay times on the order of 65-67 ns before and after $\mathrm{ZnS}$ shell growth, however, the shortest lifetime is constantly decreasing with 
A

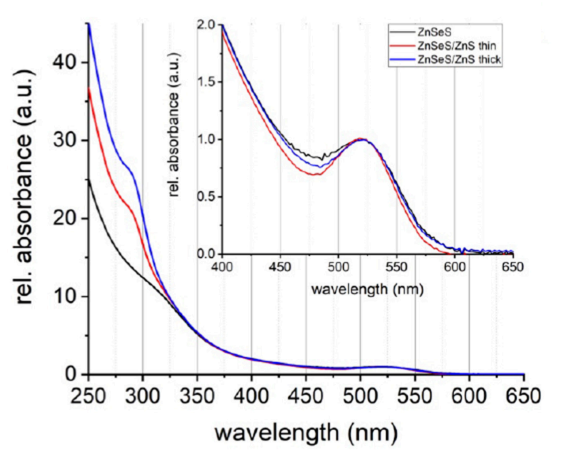

C

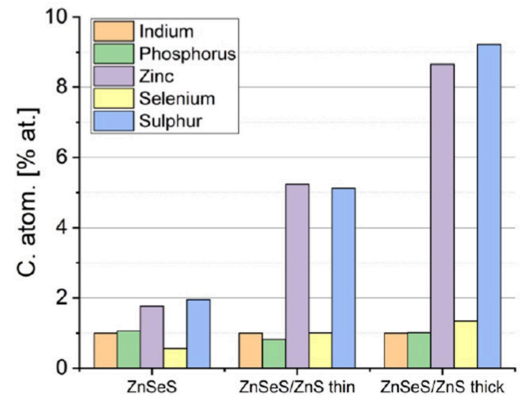

B

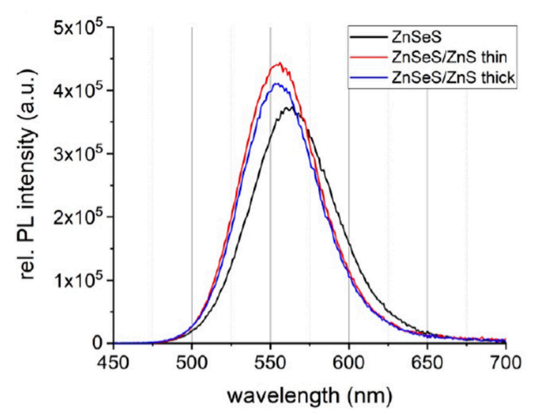

D

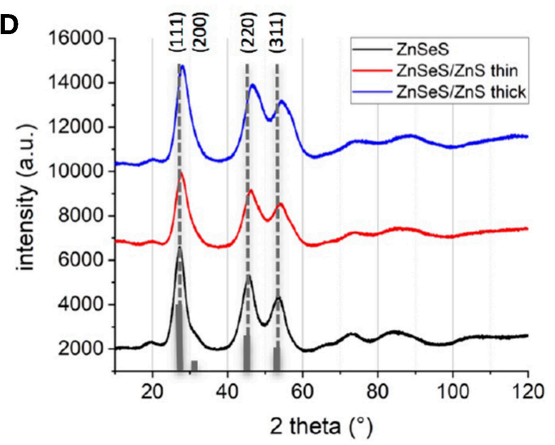

FIGURE 2 | Normalized absorbance spectra (A) and absorbance corrected PL spectra (B) of InZnP QDs with ZnSeS (black), ZnSeS/ZnS thin (red), and ZnSeS/ZnS thick shell (blue). (C) Indium normalized composition determined with EDX. (D) Powder X-ray diffractograms (Cu-Ka); the reference pattern of bulk zinc blende InP (JCPDS file \#32-0452) is added as gray bars.

increasing ZnS shell thickness, suggesting a smaller contribution of surface trap states (Wegner et al., 2019).

As an additional surface passivation step, coating with an alumina layer was explored. While this treatment has been shown to yield a significant stability enhancement of CdSe and $\mathrm{CuInS}_{2}$-based NCs (Li et al., 2015; Yan et al., 2016), it has not yet been applied to indium phosphide based QDs. To induce the formation of the alumina coating, we added a welldefined amount of aluminum isopropoxide during the growth of the (thin) ZnS shell on the gradient shell (cf. Experimental Section). While the absorption and PL spectra remain essentially unchanged with respect to the CSS system (Figure S2) and a high PL QY is maintained (48\%), aluminum treatment induces a higher value of the averaged PL decay time ( $82.8 \mathrm{~ns}$, cf. Table S3). EDX analysis shows that a significant amount of aluminum has been incorporated into the QDs with an In:Al ratio of 1:9. Such a high ratio is indeed required for forming, as hypothesized, a monolayer of alumina on an $\operatorname{In}(\mathrm{Zn}) \mathrm{P}$ core already passivated with a gradient and a thin $\mathrm{ZnS}$ shell.

\section{Photostability in PMMA}

For assessing the photostability under controlled conditions, the QDs were first integrated into a PMMA matrix. The main advantages of PMMA are its optical transparency (Figure S3), stability under irradiation, amorphous character, ease of composites processing, and the mechanical stability of the obtained monolithic materials. Figure 3 depicts the different steps of composite preparation and aging experiments. By optimizing the PMMA concentration in chloroform (30 $\mathrm{wt} \%$ ) and slow drying, homogeneous composites without air-bubbles could be obtained, suitable for optical measurements. A QD loading of $0.4 \mathrm{wt} \%$ resulted in the best compromise of film homogeneity and PL QY (cf. Table S4).

Incorporation into the PMMA matrix leads to a significant bathochromic shift of the PL emission maximum with increasing QD concentration in the composite (cf. Figure 3, Figure S4), accompanied by a small reduction of the PL line width. For the gradient shell and CSS system this shift accounts for 26 and $24 \mathrm{~nm}$ (97 meV/93 meV), respectively, while it is less pronounced in the case of the aluminum treated sample $(14 \mathrm{~nm}, 56 \mathrm{meV})$. At the same time, a significant decrease of the PLQY is observed with the retained QY following the order CSS (16.9\%, decrease: $73 \%)>$ aluminum treated $(10.1 \%$, decrease: $79 \%)>$ gradient shell $(7.6 \%$, decrease: $85 \%)$. Similar effects have been observed in other studies on QD incorporation into a PMMA matrix via physical mixing of both components (Zvaigzne et al., 2015). We attribute both phenomena (PL shift and QY decrease) to the fact that in the thick QD-polymer composite radiative or nonradiative energy or charge transfer processes take place favored by the close proximity of the QDs and their size distribution.

As already studied in close-packed InP-based QD films without polymer matrix (Ung et al., 2010a), in principle three processes can occur: (i) resonance photon reabsorption; (ii) Förster resonance energy transfer; (iii) direct excited charge 


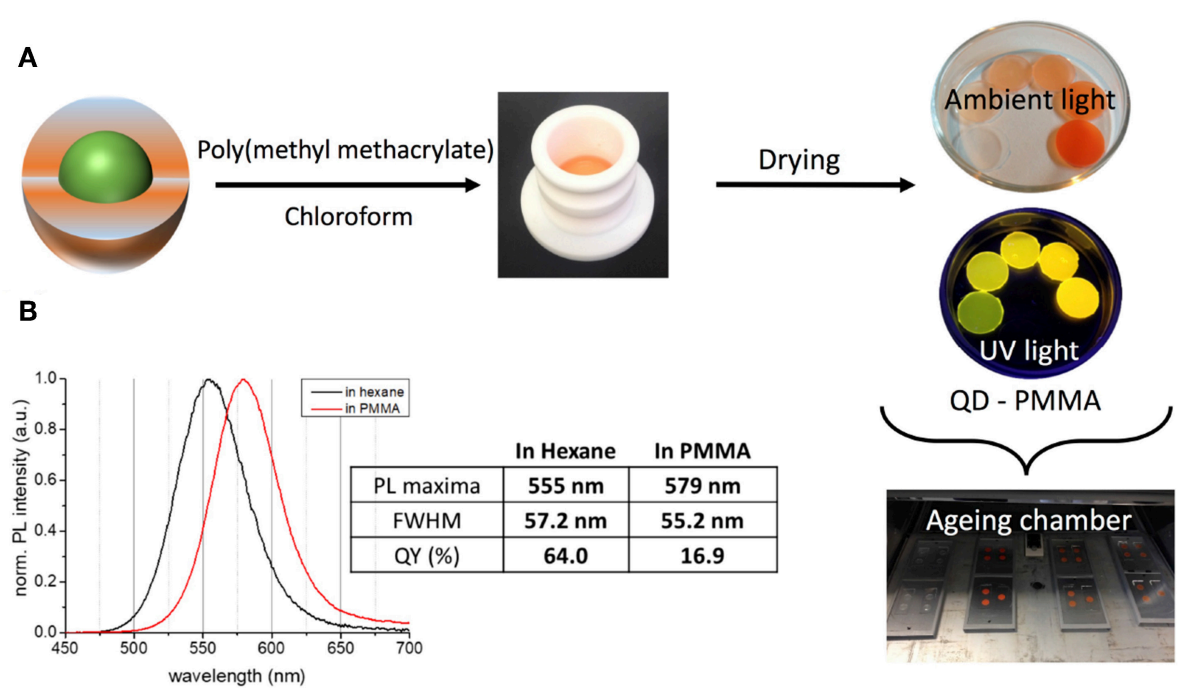

FIGURE 3 | (A) Processing of the QDs for aging experiments using a PMMA matrix and different concentrations of QDs. (B) Comparison of the PL properties of InZnP/ZnSeS/ZnS (thick shell) QDs in colloidal solution (hexane) and after embedding in the PMMA matrix.

carrier transfer from one QD to another. Due to the expected increased spatial separation of the QDs in the polymer as compared to close-packed films, process (i) could be favored here. However, it has been shown in many literature examples that the physical mixing of QDs with the polymer matrix can induce phase segregation and aggregation of the QDs (Ghimire et al., 2018). Therefore, processes (ii) and (iii) can also take place in the present case. The identification of the predominant mechanisms requires additional studies which go beyond the scope of the present work.

During $32 \mathrm{~h}$ of continuous irradiation with simulated solar light in an aging chamber at $40^{\circ} \mathrm{C}$, the gradient shell system exhibits a hypsochromic shift of the PL maximum of $55 \mathrm{meV}$, while the position of the other two samples is essentially stable (Figure 4A). Nonetheless, all samples show an increase of the emission linewidth, which is most pronounced for the gradient shell, followed by the thick shell and the aluminum treated sample (Figure 4B). The evolution of the PLQY confirms this last sample to be the most photostable one: as visible from the comparison of the relative QY loss under irradiation (Figure 4D), the gradient shell and CSS systems present identical behavior, while the aluminum treated sample maintains a higher fraction of the initial PL intensity. Intriguingly, all studied samples exhibit a very similar degradation kinetics displaying a fast PL loss during the first $6 \mathrm{~h}$ of irradiation before reaching a regime exhibiting a much slower slope and eventually a plateau for extended durations. To confirm the absence of influences arising from potential aging effects of the PMMA matrix the latter has been submitted to identical irradiation experiments on its own (i.e., without QDs) (Figure S5).

Noteworthy, the general trends of PL intensity evolution of the three systems are similar when keeping the composites at room temperature in the dark (cf. Figure S6), while no evolution of the optical properties is observed for samples kept in the colloidal state either in organic solvent or in PBS buffer after aqueous phase transfer (vide infra). In the PMMA matrix, the QY gradually decreases over time for the CSS and gradient shell systems, while it remains stable for the aluminum treated sample. In contrast to the case of solar irradiation, no fast QY loss during the first hours is observed, which clearly confirms that this fast degradation is light induced. As visible from the evolution of the normalized PL spectra with irradiation duration (Figure S7), in all three samples the contribution of trap-state emission in the 650-750 $\mathrm{nm}$ range markedly increases over time. One possible explanation for the activation of trap states and the observed PL decrease in the first $6 \mathrm{~h}$ of irradiation is lightinduced rearrangement of the nanocrystal surface (Saba et al., 2013). This process, leading ultimately to photocharging and charge trapping, is influenced in the present case by interaction of the QD surface with the polymer matrix.

\section{XPS Analysis}

To probe the change of surface chemistry of QDs as well as PMMA stability over aging, we performed XPS analyses for which the probed depth is about $5 \mathrm{~nm}$. Two samples were studied before and after $6 \mathrm{~h}$ of irradiation: $\mathrm{InZnP} / \mathrm{ZnSeS}$ gradient shell QDs, most affected by the aging, and aluminum treated CSS QDs, least affected, both embedded in the PMMA matrix. Figure 5 shows the C1s core level of the pristine and irradiated samples. The main feature of the spectra is that the signatures of PMMA are preserved after $6 \mathrm{~h}$ of irradiation, for instance the C-C $(285.0 \mathrm{eV}), \mathrm{C}-\mathrm{O}(286.7 \mathrm{eV})$, and COO $(288.7 \mathrm{eV})$ signals, indicating that PMMA remains stable during the selected aging time.

The valence change of zinc was studied through the analyses of the $\mathrm{Zn} 2 \mathrm{p}$ core peak and $\mathrm{Zn} \mathrm{L}_{3} \mathrm{M}_{45} \mathrm{M}_{45}$ Auger lines (Figure 6). The $\mathrm{Zn} 2 \mathrm{p}$ signal shows a main peak at $1022.7 \mathrm{eV}$ assigned to the + II valence state of zinc. The binding energy of $\mathrm{Zn} 2 \mathrm{p}_{3 / 2}$ does not change during aging in the case of the aluminum treated sample, while a slight shift $(+0.3 \mathrm{eV})$ to higher binding 

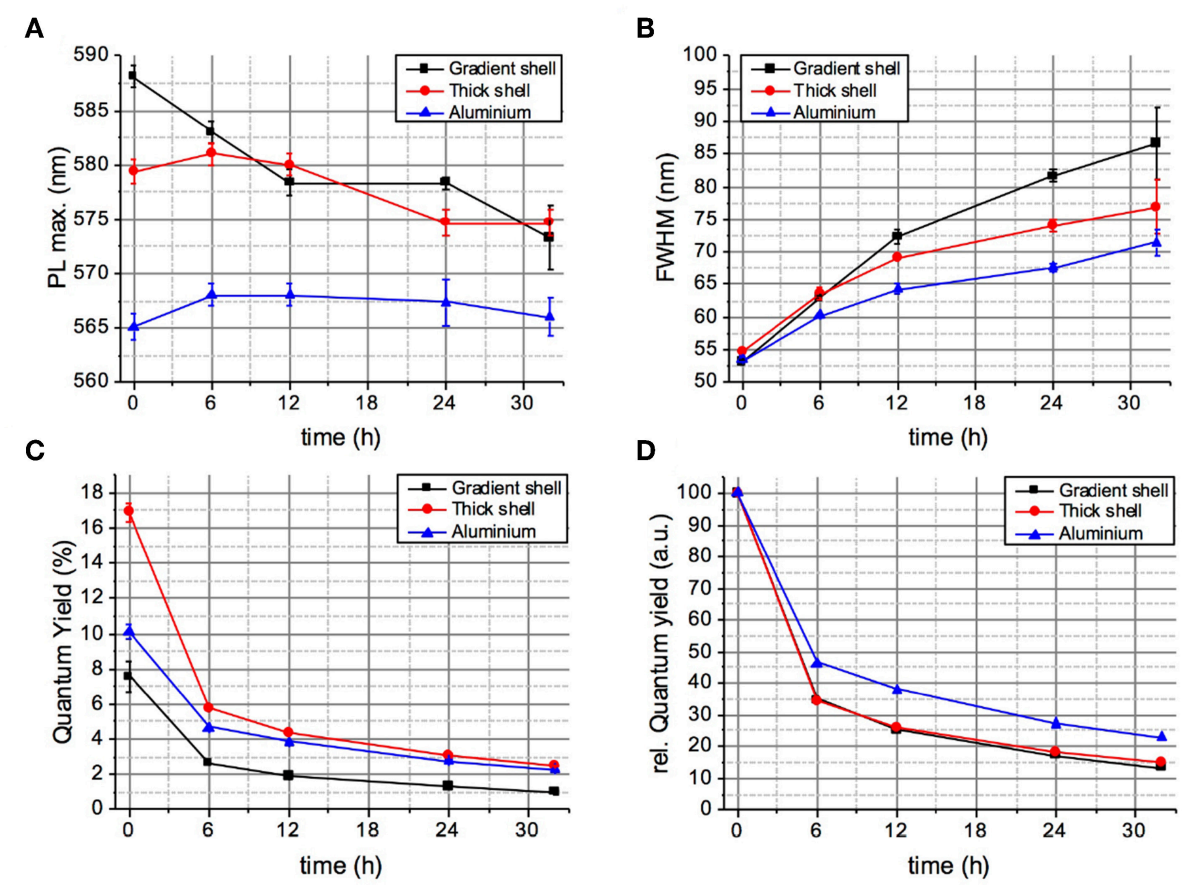

FIGURE 4 | Evolution of the PL maximum wavelength (A), linewidth (B), absolute PLQY (C), and relative PLQY (D) of the QD-PMMA composites during $32 \mathrm{~h}$ of continuous aging (irradiation with a solar simulator at $40^{\circ} \mathrm{C}$ ).
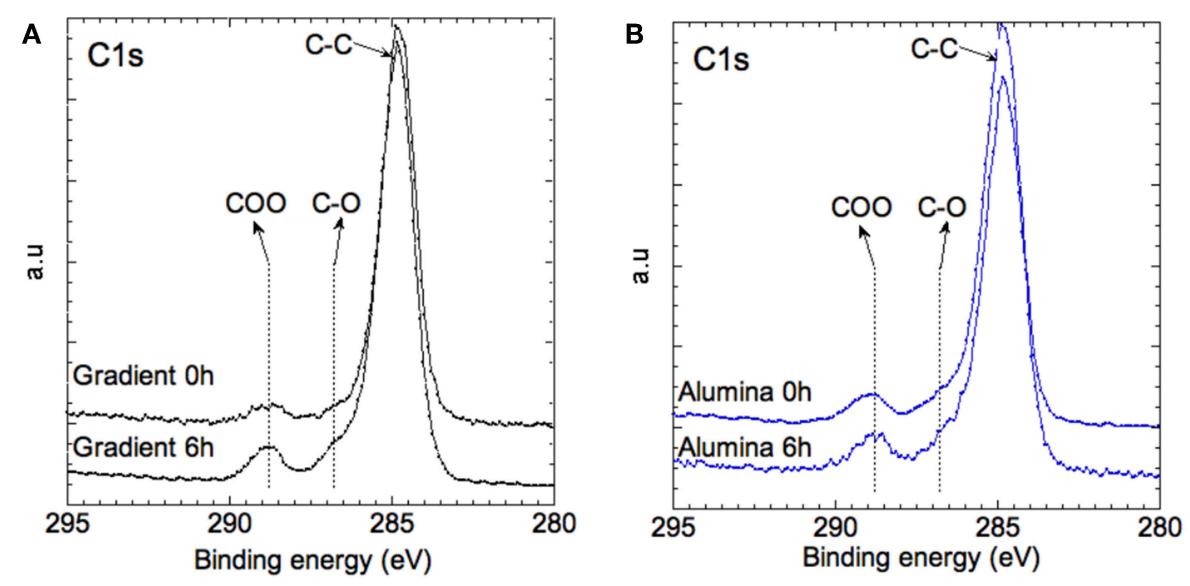

FIGURE 5 | XPS spectra of the C1s core level of (A) the gradient shell sample and (B) the aluminum treated sample at 0 and $6 \mathrm{~h}$ of aging.

energies is observed for the gradient QDs after $6 \mathrm{~h}$ of irradiation. To further investigate the chemical environment of the zinc atoms, analysis of the $\mathrm{Zn} \mathrm{L} \mathrm{L}_{3} \mathrm{M}_{45} \mathrm{M}_{45}$ Auger peaks provides detailed information, which can be extracted from the shapes, intensities, and locations of the Auger lines involving deep $\mathrm{Zn}$ $2 \mathrm{p}_{3 / 2}\left(\mathrm{~L}_{3}\right)$ and shallow $\mathrm{Zn} 3 \mathrm{~d}_{5 / 2-3 / 2}\left(\mathrm{M}_{45}\right)$ core levels. The Auger line arises from the three nearly degenerated levels $1 \mathrm{D}$, $3 \mathrm{P}$, and $1 \mathrm{G}$, and two extreme levels $1 \mathrm{~S}$ and $3 \mathrm{~F}$ constituting the higher and lower energy shoulders of the Auger line (inset of Figure 6). As a first approximation, the main peak of each chemical group can be represented by the 1D, 3P, and $1 \mathrm{G}$ triad (nX) symbolized by a dashed line (Lee et al., 2014). With these information, the Wagner parameter can be defined (Wagner, 1972):

$$
\alpha=E_{\mathrm{b}}\left(\mathrm{Zn} 2 \mathrm{p}_{3 / 2}\right)+\mathrm{E}_{\mathrm{K}}(\mathrm{Zn} \mathrm{LMM})
$$

where $E_{k}$ is the kinetic energy of the core-valencevalence Auger transition electron, and $\mathrm{E}_{\mathrm{b}}$ the binding energy of the $\mathrm{Zn} 2 \mathrm{p}_{3 / 2}$ core electron referred to the Fermi energy. 

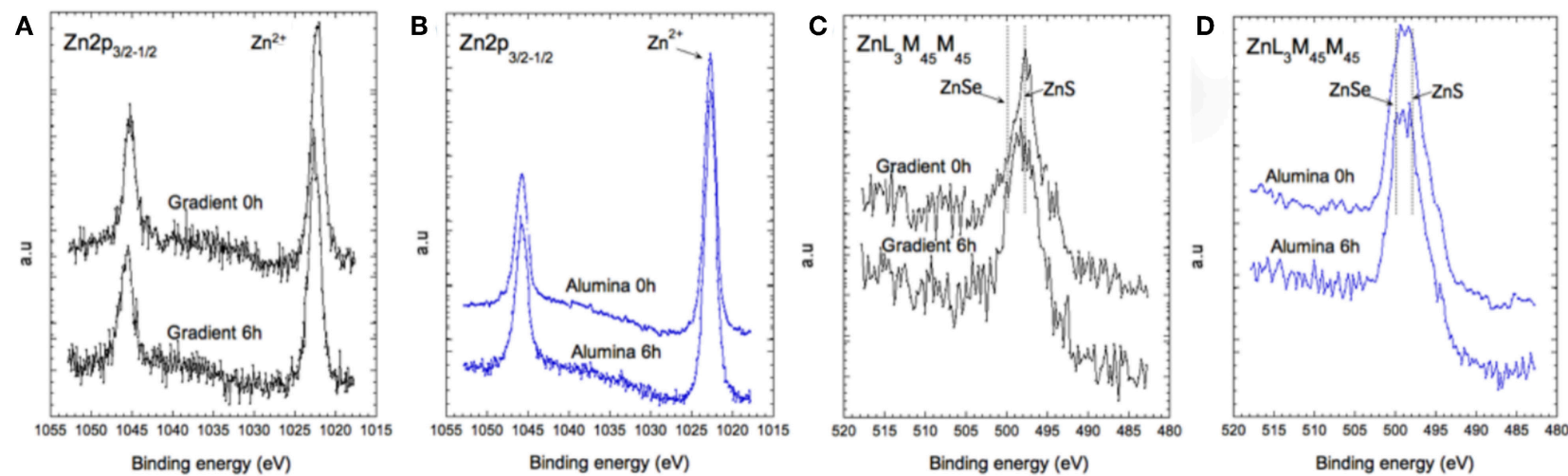

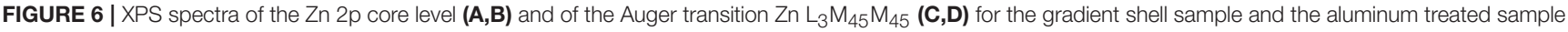
at 0 and at $6 \mathrm{~h}$ of aging.

Materials with similar Wagner parameters have closely similar extra-atomic relaxation arising from multiplet coupling in the final states, i.e., the extra-atomic polarization energy and the local electronic structure of the material. Hence, we can distinguish at least three families of zinc-ligand species for both types of samples (gradient shell and aluminum treated), since we can extract at least three Wagner parameters: $\alpha_{1}$ at $2009.6 \mathrm{eV}, \alpha_{2}$ at $2011.1 \mathrm{eV}$ and $\alpha_{3}$ at $2013.1 \mathrm{eV}$. They can be assigned to zinc in $\mathrm{ZnSe}, \mathrm{ZnS}$, and $\mathrm{Zn}$-Zn chemical environment, respectively. At this stage, the contribution of the $\mathrm{ZnSe}$ and $\mathrm{ZnS}$ phases is difficult to quantify from the spectral signature. However, it appears that in the case of the aluminum treated QDs the zinc related environment remains stable over time. In the case of the gradient shell QDs, the ZnS related bonds are dominant in the pristine material and decrease after $6 \mathrm{~h}$ of aging, while the ZnLMM spectral shape becomes similar to that recorded in the case of aluminum treated QDs.

Figures 7A,B reports the Se $3 \mathrm{~d}$ core level of both systems. In the case of the gradient shell, the spectra show one doublet at $54.1-55.0 \mathrm{eV}$ (associated to spin-orbit coupling), signature of $\mathrm{Se}^{2-}$ ions in $\mathrm{ZnSe}$. In the case of the aluminum treated QDs, we observe two doublets at 54.1-55.0 and 54.9-55.8 eV associated with $\mathrm{ZnSe}$ and $\mathrm{ZnSe}_{\mathrm{x}} \mathrm{S}_{(1-\mathrm{x})}$, respectively. These differences are unexpected, as the core and gradient shell were synthesized in the same manner for both systems. On the other hand, as the additional growth steps in the case of the alumina-capped sample imply prolonged heating to $230^{\circ} \mathrm{C}$, a more pronounced interdiffusion of the $\mathrm{ZnSe}$ and $\mathrm{ZnS}$ phases may take place giving rise to the mixed $\mathrm{ZnSe}_{\mathrm{X}} \mathrm{S}_{(1-\mathrm{x})}$ phase. The $\mathrm{S} 2 \mathrm{p}$ doublet (Figure 7D) at $162-164 \mathrm{eV}$ is the signature of $\mathrm{S}^{2-}$ ions in $\mathrm{ZnS}$ environment. The $\mathrm{ZnS}: \mathrm{ZnSe}$ ratio remains stable during aging (cf. Table S5). For the gradient shell, the presence of oxidized sulfur $\left(-\mathrm{SO}_{4}\right)$ is observed (Figure $7 \mathrm{C}$ ) whose concentration increases slightly after aging.

At a first approximation, the In $3 \mathrm{~d}_{5 / 2}$ peak recorded at the surface centered at $445.4 \mathrm{eV}$ can be assigned to $\mathrm{In}^{3+}$ ions in $\mathrm{In}_{2} \mathrm{O}_{3}$ and/or In $(\mathrm{OH})_{3}$. The presence of In $(\mathrm{S}, \mathrm{Se}$, P) cannot be excluded since the P 2p core level peak (not shown) exhibits two contributions, a major one around $134 \mathrm{eV}$ attributed to phosphate groups (InPOx) and a low intensity peak around $130 \mathrm{eV}$ assigned to In-P bonds (Figure 8). Oxidation of the core/shell interface in InP-based QDs occurring during the synthesis under similar experimental conditions has been reported by Delpech and coworkers (Virieux et al., 2012). It has been attributed to the in situ generation of minute amounts of water due to side reactions of the fatty acid ligands (e.g., myristate, stearate).

In the case of the aluminum treated sample, the ratio between both indium species remains quasi-stable whereas in the case of the gradient system significate changes are observed (Figures 8A,B).

The $\mathrm{Al} 2 \mathrm{p}$ core level is the signature of $\mathrm{Al}^{3+}$ like in $\mathrm{Al}_{2} \mathrm{O}_{3}$. It stays the same after $6 \mathrm{~h}$ of aging, confirming that the aluminum coating is very stable and does not degrade under irradiation (Figure 8C). Taken together, the presented XPS results fully underpin the stability differences of the two systems expected from the photophysical studies. In the case of the gradient shell, the initial $\mathrm{ZnS}$ outer layer already shows distinct signs of oxidation right from the start (-SO $\mathrm{SO}_{4}$ species), which are not detectable in the aluminum treated sample. Furthermore, during the aging process the degradation of the gradient shell sample continues, as visible by the XPS spectral changes, in particular the decrease of the signals characteristic for $\mathrm{ZnS}$ related bonds and increase of the oxidized indium component. The latter implies a reduction of the emissive core size, which is supposed to be at the origin of the observed hypsochromic shift of the PL maximum (cf. Figure 4A).

\section{Cytotoxicity Studies}

Aqueous phase transfer of the QDs was achieved by surface ligand exchange with zwitterionic penicillamine (Figure 9) (Tamang et al., 2011; Mattera et al., 2016). In this procedure, the QDs in chloroform are brought into intimate contact with an aqueous solution of penicillamine. The $\mathrm{pH}$ of the aqueous phase is adjusted in the basic range (around 9), to favor the deprotonation of the thiol moiety leading to efficient binding to the ZnS surface of the QDs. In the case of the alumina-coated system, however, this approach was not successful. Other types 

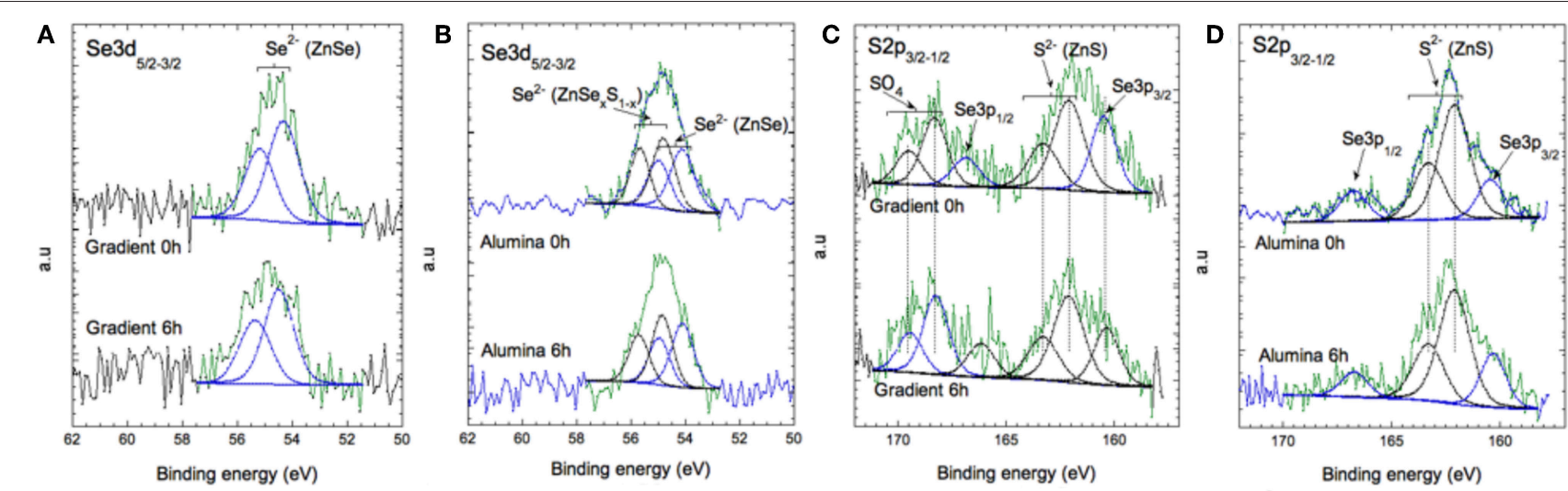

FIGURE 7 | XPS spectra of Se 3d (A,B) and of S 2p and Se 3p (C,D) for the gradient shell sample and the aluminum treated sample at 0 and $6 \mathrm{~h}$ of aging.
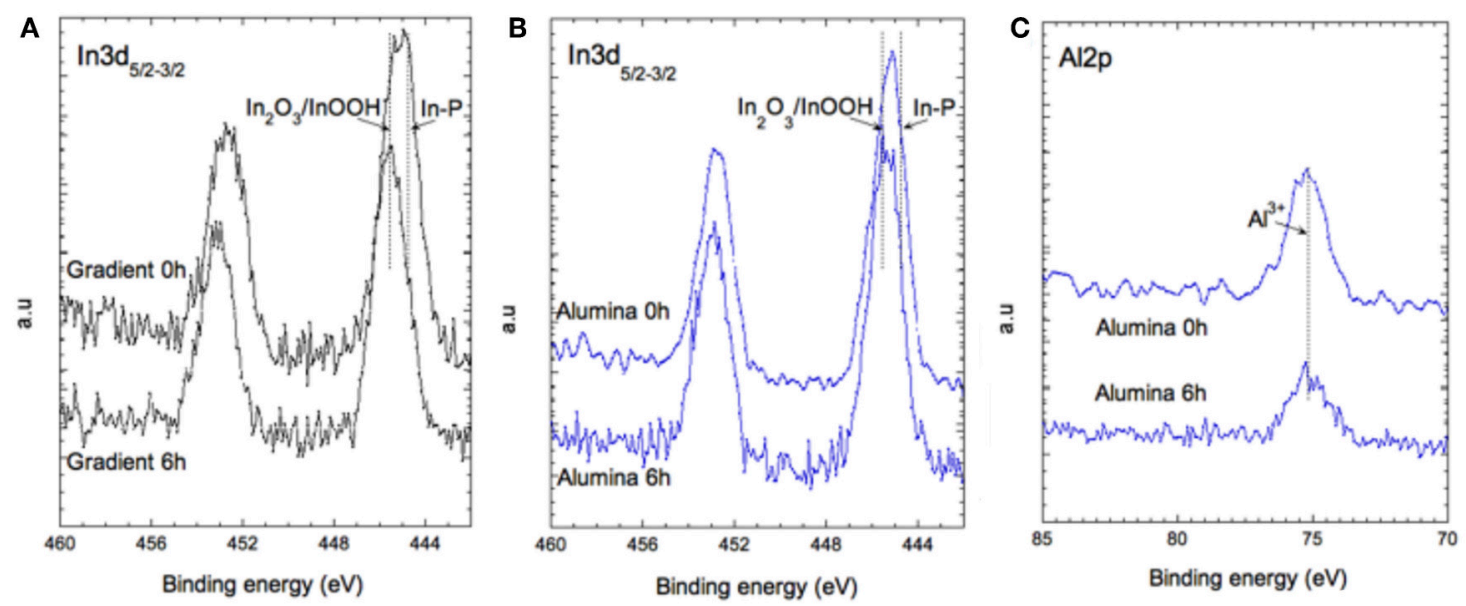

FIGURE 8 | XPS spectra of In 3d for (A) the gradient shell sample and (B) the aluminum treated sample at 0 and $6 \mathrm{~h}$ of aging. (C) XPS spectra of Al $2 \mathrm{p}$ for the aluminum treated sample.

of surface chemistries have to be developed there, which are the subject of ongoing research. Therefore, in the remaining part of this article we will focus on the core/shell systems without aluminum treatment.

While the absorbance properties are not affected by the phase transfer, the PL peaks exhibit a bathochromic shift of around 10-15 $\mathrm{nm}$ accompanied by a slight line broadening (Table S6). The PL intensity strongly depends on the shell thickness of the QDs as seen in the photograph in Figure 9A and in the spectra in Figure 9B. As generally observed in phase transfer methods applying direct surface ligand exchange, the PLQY significantly decreases. This decrease is particularly pronounced for the gradient shell sample (QY: 6.0\%) whereas the systems with additional $\mathrm{ZnS}$ shells exhibit enhanced PL conservation (QY: 15.5\% CSS thin; $17.1 \%$ CSS thick). The gradient shell sample shows a significant decrease in the average decay time after phase transfer and a concomitant increase of the amplitude of the shortest lifetime (Figure S8, Table S7). All three systems exhibit an increase of the latter, albeit the trend of the contribution of the short lifetime component is maintained in the order gradient shell $>$ CSS thin $>$ CSS thick, as in the samples before phase transfer. All in all, these results indicate that surface trap states induced by the ligand exchange reaction are at the origin of the PLQY decrease. As expected this detrimental effect can be reduced by increasing the shell thickness. Dynamic light scattering (DLS) measurements (Figure S9) confirm the absence of larger-sized aggregates. The hydrodynamic diameters of the samples extracted from DLS are consistent with the values obtained from TEM analysis (Figure S10). However, the precise determination of the QD sizes is challenging due to the low contrast of the ZnS shell in TEM and the small diameters in the 4-6 $\mathrm{nm}$ range.

Since the QDs are synthesized in liquid phase with no risk of aerosolisation, the most probable exposure route for humans is through skin contact (Reiss et al., 2016). Impact of these QDs was assessed in vitro on skin cells, i.e., primary keratinocytes isolated from human donors. As shown in Figure 10A, exposure to 6.5-100 nM of QDs for $24 \mathrm{~h}$ do not 

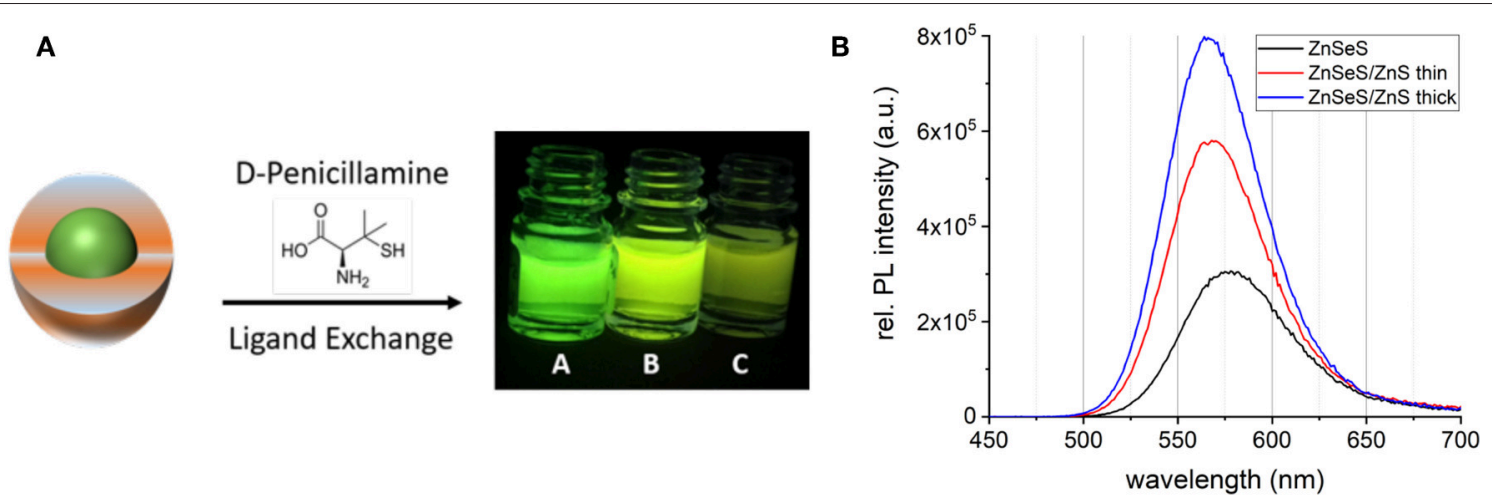

FIGURE 9 | (A) Schematic representation of the aqueous phase transfer using penicillamine. The photograph shows the phase transferred samples: InZnP/ZnSeS/ZnS thick (A), InZnP/ZnSeS/ZnS thin (B), and InZnP/ZnSeS (C) in PBS buffer. (B) Absorbance corrected PL spectra of the phase-transferred samples.
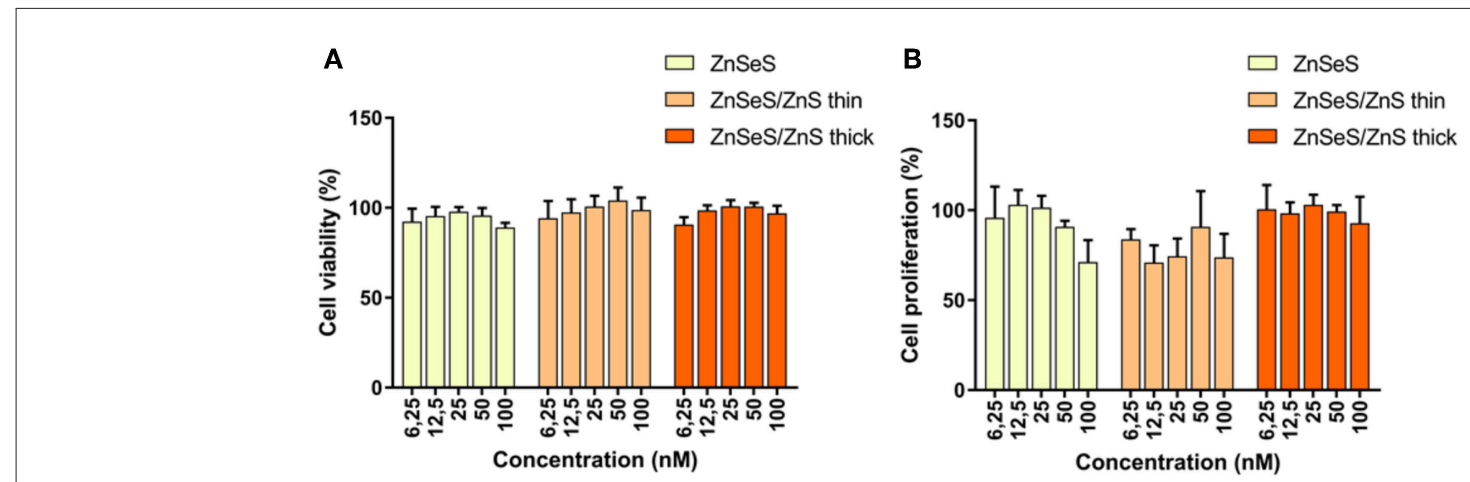

FIGURE 10 | Cell viability (A) and cell proliferation (B) of human keratinocytes exposed to increasing concentrations of QDs with different shells.

cause any leakage of lactate dehydrogenase from cells, i.e., do not affect cell membrane integrity, which is classically used as a proxy for cell viability. BrdU, an analog of the nucleoside thymidine which is incorporated into DNA during replication, was used as an indicator of QD impact on cell proliferation. A trend toward reduced cell proliferation is observed in cells exposed to QDs (Figure 10B). This trend is observed in cells exposed to QDs with a gradient shell and CSS with a thin shell, but not to CSS with a thick shell. This shows that the thick shell not only facilitates the phase transfer and preserves best the photophysical properties but is also beneficial from a cytotoxicity point of view. These features combined with the compact size of the penicillamine-capped CSS QDs make them particularly interesting for further applications in biosensing.

\section{CONCLUSIONS}

With the goal to improve the photostability of InP-based QDs, we have synthesized three different types of core/shell structures. The first one uses a $\mathrm{ZnSe}_{\mathrm{x}} \mathrm{S}_{1-\mathrm{x}}$ gradient shell as reported by Lim et al. (2011). In the second, CSS system, additional growth of a $\mathrm{ZnS}$ shell of controlled thickness on top of the gradient shell has been undertaken, using the monomolecular precursor zinc ethylxanthate (Protiere and Reiss, 2006). Finally, in the third system alumina coating was performed on top of the $\mathrm{ZnS}$ shell. When incorporated into a PMMA matrix and submitted to continuous irradiation in a climate chamber, the three systems exhibit distinctly different behavior. While all of them show a marked drop of QY within the first $6 \mathrm{~h}$ of irradiation, the aluminum treated sample retains most of the initial PL intensity. The gradient shell and CSS systems show a minor but continuous loss of QY also in the dark, which is attributed to the interaction of the PMMA matrix with the Zn-based shell. It has been shown that PMMA-type polymers can act as efficient sorbents for $\mathrm{Zn}$ (II) ion removal (Jakóbik-Kolon et al., 2017). To the contrary, the aluminum treated sample is fully stable in the dark.

XPS studies revealed that upon irradiation the degradation of the $\mathrm{ZnS}$ outer layer and oxidation of the $\operatorname{In}(\mathrm{Zn}) \mathrm{P}$ core are at the origin of the observed decrease of PL intensity and hypsochromic shift of the PL maximum. XPS also confirmed the formation of an $\mathrm{Al}_{2} \mathrm{O}_{3}$-type layer in the case of the aluminum treated sample, which effectively protects against degradation. The chemical stability of the alumina capped sample being thus demonstrated, the observed decrease of PLQY upon continuous irradiation is ascribed to light-induced surface reconstruction. The modification of the configuration of surface 
atoms and capping ligands can introduce defect states favoring photocharging of the QDs and charge carrier trapping. Similar processes are also at work in the case of the gradient and CSS systems, in addition to photo-oxidation. These detrimental effects could likely be overcome by increasing the inorganic shell thickness, providing a more efficient separation of the emissive core and the environment.

With the gradient shell and CSS systems phase transfer was achieved using surface ligand exchange with penicillamine and a clear correlation between the retained PLQY and shell thickness was observed. Cytotoxicity studies indicate that the different types of QDs do not influence the cell viability of human keratinocytes. On the other hand, a trend of reduced cell proliferation is observed for cells exposed to higher concentrations of gradient shell and CSS QDs with a thin $\mathrm{ZnS}$ outer shell. This trend is not visible for the CSS QDs with a thicker ZnS shell, confirming both the necessity and advantageous features of thicker shells protecting InP-based QDs. Ongoing studies concern the aqueous phase transfer of alumina-coated QDs, either via encapsulation with ambipolar macromolecules (e.g., phospholipids) or through the identification of appropriate bifunctional molecules for ligand exchange. Furthermore, with the goal to reduce PL losses during the $\mathrm{QD}$ incorporation in the matrix, different types of suitable polymers (e.g., polystyrene, polydimethylsiloxane, or block copolymers) deserve attention as well as approaches preventing from undesired phase-segregation of the QDs and the polymer by introducing specific interactions between both components (Ghimire et al., 2018).

Concluding, the presented results contribute to the better understanding of the degradation mechanisms of core/shell QDs and to the development of InP-based QD heterostructures combining enhanced chemical and photostability, bringing them closer to the requirements of real-life applications.

\section{DATA AVAILABILITY}

All datasets generated for this study are included in the manuscript and/or the Supplementary Files.

\section{REFERENCES}

Allocca, M., Mattera, L., Bauduin, A., Miedziak, B., Moros, M., De Trizio, L., et al. (2019). An integrated multilevel analysis profiling biosafety and toxicity induced by indium- and cadmium-based quantum dots in vivo. Environ. Sci. Technol. 53, 3938-3947. doi: 10.1021/acs.est.9b0 0373

Chandrasekaran, V., Tessier, M. D., Dupont, D., Geiregat, P., Hens, Z., and Brainis, E. (2017). Nearly blinking-free, high-purity single-photon emission by colloidal InP/ZnSe quantum dots. Nano Lett. 17, 6104-6109. doi: 10.1021/acs.nanolett.7b02634

Cossairt, B. M. (2016). Shining light on indium phosphide quantum dots: understanding the interplay among precursor conversion, nucleation, and growth. Chem. Mater. 28, 7181-7189. doi: 10.1021/acs.chemmater.6b03408

Ghimire, S., Sivadas, A., Yuyama, K.-I., Takano, Y., Francis, R., and Biju, V. (2018). Quantum dot-polymer conjugates for stable luminescent displays. Nanoscale 10, 13368-13374. doi: 10.1039/C8NR01501E

\section{AUTHOR CONTRIBUTIONS}

MC and PR conceived and designed the study. KW performed the synthetic work and data analysis with assistance of PR and MC. AB performed the XPS studies and analysis. DT-B carried out the aging experiments and assisted in the XPS analysis. FD and DB performed cytotoxicity studies. LM helped with QD phase transfer. WL performed transmission electron microscopy. PR wrote the manuscript with assistance of KW and MC. All authors contributed to its finalization.

\section{FUNDING}

This work is a contribution to the Labex Serenade (ANR11-LABX-0064) funded by the French Government's Investissements d'Avenir ANR program, through the A*MIDEX project (ANR-11-IDEX-0001-02). The authors thank the French National Research agency ANR for financial support (grants NEUTRINOS, ANR-16-CE09-0015-03 and FLUO, ANR-18CE09-0039-01). We thank the CEA DRF Impulsion program (Cryo-ME_NP) for partial financial support of this work. This work used the platforms of the Grenoble Instruct-ERIC Centre (ISBG; UMS 3518 CNRS-CEA-UGA-EMBL) with support from FRISBI (ANR-10-INSB-05-02) and GRAL (ANR-10-LABX49-01) within the Grenoble Partnership for Structural Biology (PSB). The IBS electron microscope facility is supported by the Auvergne-Rhône-Alpes Region, the fonds FEDER, the Fondation Recherche Médicale (FRM), C GIS-IBISA.

\section{ACKNOWLEDGMENTS}

We thank the electron microscopy platform, especially Dr. G. Schoehn and Dr. M. Bacia.

\section{SUPPLEMENTARY MATERIAL}

The Supplementary Material for this article can be found online at: https://www.frontiersin.org/articles/10.3389/fchem. 2019.00466/full\#supplementary-material

Huang, K., Demadrille, R., Silly, M. G., Sirotti, F., Reiss, P., and Renault, O. (2010). Internal structure of InP/ZnS nanocrystals unraveled by highresolution soft X-ray photoelectron spectroscopy. ACS Nano 4, 4799-4805. doi: 10.1021/nn100581t

Jakóbik-Kolon, A., Milewski, A., Zdybał, D., Mitko, K., Laskowska, E., Mielanczyk, A., et al. (2017). Zinc sorption on modified waste poly (methyl methacrylate). Materials 10:755. doi: 10.3390/ma10070755

Lee, E., Benayad, A., Shin, T., Lee, H., Ko,s D.-S., Kim, T. S., et al. (2014). Nanocrystalline ZnON; High mobility and low band gap semiconductor material for high performance switch transistor and image sensor application. Sci. Rep. 4:4948. doi: 10.1038/srep06897

Li, L., and Reiss, P. (2008). One-pot synthesis of highly luminescent InP/ZnS nanocrystals without precursor injection. J. Am. Chem. Soc. 130, 11588-11589. doi: $10.1021 /$ ja803687e

Li, Z., Yao, W., Kong, L., Zhao, Y., and Li, L. (2015). General method for the synthesis of ultrastable core/shell quantum dots by aluminum doping. J. Am. Chem. Soc. 137, 12430-12433. doi: 10.1021/jacs.5b05462 
Lim, J., Bae, W. K., Lee, D., Nam, M. K., Jung, J., Lee, C., et al. (2011). InP@ZnSeS, Core@Composition gradient shell quantum dots with enhanced stability. Chem. Mater. 23, 4459-4463. doi: 10.1021/cm201550w

Lim, J., Park, M., Bae, W. K., Lee, D., Lee, S., Lee, C., et al. (2013). Highly efficient cadmium-free quantum dot light-emitting diodes enabled by the direct formation of excitons within InP@ZnSeS quantum dots. ACS Nano 7, 9019-9026. doi: 10.1021/nn403594j

Mattera, L., Bhuckory, S., Wegner, K. D., Qiu, X., Agnese, F., Lincheneau, C., et al. (2016). Compact quantum dot-antibody conjugates for FRET immunoassays with subnanomolar detection limits. Nanoscale 8, 11275-11283. doi: 10.1039/C6NR03261C

Mouret, S., Baudouin, C., Charveron, M., Favier, A., Cadet, J., and Douki, T. (2006). Cyclobutane pyrimidine dimers are predominant DNA lesions in whole human skin exposed to UVA radiation. Proc. Natl. Acad. Sci. USA. 103, 13765-13770. doi: 10.1073 /pnas.0604213103

Pietra, F., De Trizio, L., Hoekstra, A. W., Renaud, N., Prato, M., Grozema, F. C., et al. (2016). Tuning the lattice parameter of InxZnyP for highly luminescent lattice-matched core/shell quantum dots. ACS Nano 10:4754. doi: 10.1021/acsnano.6b01266

Protiere, M., and Reiss, P. (2006). Facile synthesis of monodisperse ZnS capped CdS nanocrystals exhibiting efficient blue emission. Nanoscale Res. Lett. 1, 62-67. doi: 10.1007/s11671-006-9001-0

Ramasamy, P., Kim, N., Kang, Y.-S., Ramirez, O., and Lee, J.-S. (2017). Tunable, bright, and narrow-band luminescence from colloidal indium phosphide quantum dots. Chem. Mater. 29, 6893-6899. doi: 10.1021/acs.chemmater.7b02204

Reiss, P., Carayon, S., Bleuse, J., and Pron, A. (2003). Low polydispersity core/shell nanocrystals of CdSe/ZnSe and CdSe/ZnSe/ZnS type: preparation and optical studies. Synth. Met. 139, 649-652. doi: 10.1016/S0379-6779 (03)00335-7

Reiss, P., Carrière, M., Lincheneau, C., Vaure, L., and Tamang, S. (2016). Synthesis of semiconductor nanocrystals, focusing on nontoxic and earth-abundant materials. Chem. Rev. 116, 10731-10819. doi: 10.1021/acs.chemrev.6b00116

Reiss, P., Protiere, M., and Li, L. (2009). Core/shell semiconductor nanocrystals. Small 5, 154-168. doi: 10.1002/smll.200800841

Saba, M., Aresti, M., Quochi, F., Marceddu, M., Loi, M. A., Huang, J., et al. (2013). Light-induced charged and trap states in colloidal nanocrystals detected by variable pulse rate photoluminescence spectroscopy. ACS Nano 7, 229-238. doi: $10.1021 / \mathrm{nn} 305031 \mathrm{k}$

Stein, J. L., Mader, E. A., and Cossairt, B. M. (2016). Luminescent InP quantum dots with tunable emission by post-synthetic modification with lewis acids. J. Phys. Chem. Lett. 7, 1315-1320. doi: 10.1021/acs.jpclett.6b00177

Talapin, D. V., Mekis, I., Gotzinger, S., Kornowski, A., Benson, O., and Weller, H. (2004). CdSe/CdS/ZnS and CdSe/ZnSe/ZnS core-shell-shell nanocrystals. J. Phys. Chem. B 108, 18826-18831. doi: 10.1021/jp046481g

Tamang, S., Beaune, G., Texier, I., and Reiss, P. (2011). Aqueous phase transfer of InP/ZnS nanocrystals conserving fluorescence and high colloidal stability. ACS Nano 5, 9392-9402. doi: 10.1021/nn203598c

Tamang, S., Lincheneau, C., Hermans, Y., Jeong, S., and Reiss, P. (2016). Chemistry of InP nanocrystal syntheses. Chem. Mater. 28, 2491-2506. doi: 10.1021/acs.chemmater.5b05044
Tessier, M. D., Dupont, D., De Nolf, K., De Roo, J., and Hens, Z. (2015). Economic and size-tunable synthesis of $\mathrm{InP} / \mathrm{ZnE}(\mathrm{E}=\mathrm{S}$, Se) colloidal quantum dots. Chem. Mater. 27, 4893-4898. doi: 10.1021/acs.chemmater.5b02138

Toufanian, R., Piryatinski, A., Mahler, A. H., Iyer, R., Hollingsworth, J. A., and Dennis, A. M. (2018). Bandgap engineering of indium phosphide-based core/shell heterostructures through shell composition and thickness. Front. Chem. 6:567. doi: 10.3389/fchem.2018.00567

Ung, T. D. T., Pham, T. T., Nguyen, Q. L., Li, L., and Reiss, P. (2010a). Comparative photoluminescence study of close-packed and colloidal InP/ZnS quantum dots. Appl. Phys. Lett. 96:073102. doi: 10.1063/1.3291049

Ung, T. D. T., Reiss, P., and Nguyen, Q. L. (2010b). Luminescence properties of $\operatorname{In}(\mathrm{Zn}) \mathrm{P}$ alloy core/ZnS shell quantum dots. Appl. Phys. Lett. 97:193104. doi: 10.1063/1.3515417

Virieux, H., Le Troedec, M., Cros-Gagneux, A., Ojo, W.-S., Delpech, F., Nayral, C., et al. (2012). InP/ZnS nanocrystals: coupling NMR and XPS for fine surface and interface description. J. Am. Chem. Soc. 134, 19701-19708. doi: $10.1021 /$ ja307124m

Wagner, C. D. (1972). Auger lines in x-ray photoelectron spectrometry. Anal. Chem. 44, 967-973. doi: 10.1021/ac60314a015

Wang, H. C., Zhang, H., Chen, H. Y., Yeh, H. C., Tseng, M. R., Chung, R. J., et al. (2017). Cadmium-free InP/ZnSeS/ZnS heterostructure-based quantum dot light-emitting diodes with a $\mathrm{ZnMgO}$ electron transport layer and a brightness of over $10000 \mathrm{~cd} \mathrm{~m}-2$. Small 13:1603962. doi: 10.1002/smll.201603962

Wegner, K. D., Pouget, S., Ling, W. L., Carrière, M., and Reiss, P. (2019). Gallium - a versatile element for tuning the photoluminescence properties of InP quantum dots. Chem. Commun. 55, 1663-1666. doi: 10.1039/C8CC09 $740 \mathrm{~B}$

$\mathrm{Xu}$, S., Ziegler, J., and Nann, T. (2008). Rapid synthesis of highly luminescent InP and InP/ZnS nanocrystals. J. Mater. Chem. 18, 2653-2656. doi: $10.1039 / \mathrm{b} 803263 \mathrm{~g}$

Yan, L., Li, Z., Sun, M., Shen, G., and Li, L. (2016). Stable and flexible CuInS2/ZnS:Al-TiO2 film for solar-light-driven photodegradation of soil fumigant. ACS Appl. Mater. Interfaces 8, 20048-20056. doi: 10.1021/acsami.6b05587

Zvaigzne, M., Martynov, I., Samokhvalov, P., Mochalov, K., and Chistyakov, A. (2015). Influence of surface ligands on the luminescent properties of cadmium selenide quantum dots in a polymethylmethacrylate matrix. Phys. Procedia 73, 150-155. doi: 10.1016/j.phpro.2015.09.140

Conflict of Interest Statement: The authors declare that the research was conducted in the absence of any commercial or financial relationships that could be construed as a potential conflict of interest.

Copyright (c) 2019 Wegner, Dussert, Truffier-Boutry, Benayad, Beal, Mattera, Ling, Carriere and Reiss. This is an open-access article distributed under the terms of the Creative Commons Attribution License (CC BY). The use, distribution or reproduction in other forums is permitted, provided the original author(s) and the copyright owner(s) are credited and that the original publication in this journal is cited, in accordance with accepted academic practice. No use, distribution or reproduction is permitted which does not comply with these terms. 